\title{
What's in Store for Yeast Biotechnology? - The Joint 3rd Swiss-Czech and BioTech2005 Symposium in Retrospect
}

\section{Scope of the Symposium}

The joint 3rd Swiss-Czech and BioTech2005 Symposium held at the University of Applied Sciences in Wädenswil was a unique event [1][2]. The term 'symposium' is derived from the Greek verb 'sympotein', meaning to drink together [3]. The Hellenic symposia are linked to the academic symposia of today by a passion for debate, usually accompanied by other social activities. It was in this way that, for three days (17-19 May 2005), more than 150 attendees from seven European countries generated fruitful and friendly discussions on the further potential of the industrial use of yeasts such as Pichia, Saccharomyces, Hansenula and the like. The symposium brought together participants from different backgrounds and with different areas of interest: academic and industrial researchers met those involved in industrial production, and bioprocess engineers came together with chemists and (molecular) biologists. To reflect this cross-disciplinary concept, four topical sessions were included in the programme:

- Yeast Genetics and Posttranslational Modifications

- Yeast Physiology and Metabolism

- Potential Application of Yeast and Yeast Products

- Challenges in Industrial Production with Yeasts

The overall focus linking the aforementioned topics was 'Advances in Yeast Biotechnology'. Unfortunately, this special edition of CHIMIA is unable to give details of all the 17 oral and 38 poster presentations [1] and for this reason has used a 'first-come-firstserve' criterion for paper selection. A short review of the whole symposium is therefore included in this editorial.

\section{Why a Swiss-Czech Symposium?}

The Czech Republic has a long tradition in biotechnology, which includes much more than just the traditional brewing of beer. The roots of Czech biotechnology go back to the 19th century when the Augustinian monk Georg Mendel used his laws of heredity to lay the foundations for classical and molecular genetics. Today's industrial bioengineering has mainly emerged from the original chemical research at the Institute of Chemical Technology in Prague, where Vladimir Prelog, the 1975 Nobel-Prize winner for "his research into the stereochemistry of organic molecules and reactions" and a long-term professor at the ETH Zürich, completed his studies in 1929. During the late 1950s and the mid-1960s the Czech 'school' led the area of microbial cultivation, one of the high points being the publication of Málek \& Fencl's book [4] comprising the fundamentals of microbial cultivation as well as a wealth of original ideas. This outstanding research also found resonance at Swiss Universities and numerous continuing dynamic long-standing academic relationships began. In addition, commercial relationships between the Czech Republic and Switzerland have become well established. For example, the Swiss company Lonza AG, which owns a state-of-the-art facility located 50 $\mathrm{km}$ east of Prague, has been a recognized player in the Czech economy for over 15 years and is currently the largest biotech company in the Czech Republic [5].

For these reasons, Prague was chosen to host the first two Swiss-Czech Symposia on Advanced Biotechnology in 1999 [6] and 2002. These initial symposia purposely covered a broad spectrum of different scientific topics. Their main aims were, however, to create a platform for contacts, to present academic and industrial activities, and to trigger collaborations. Continuing in the tradition of these bi-national symposia, the majority of participants in the 2005 Symposium on 'Advances in Yeast Biotechnology' also stemmed from the Czech Republic and Switzerland. The venue and choice of topics for this 3rd Swiss-Czech Symposium were inspired by the Eureka-project [7] on the improvement of yeast production processes, which was launched in 2004 by the University of Applied Sciences Wädenswil, the Institute of Chemical Technology Prague, and Lonza's Kourim and Visp sites. The Fig. shows the geographical locations of the four project partners, who were the main organisers of the 2005 Swiss-Czech Symposium.

\section{Is Yeast Biotechnology of Industrial Relevance?}

Although yeast has been used by mankind since ancient times, it has had surprisingly little application as a production organism for therapeutic proteins, fine chemicals or any other industrially relevant sector [8]. This is surprising as research publications on yeasts [9-13] demonstrate its considerable potential in several areas of application and also document particular examples of 


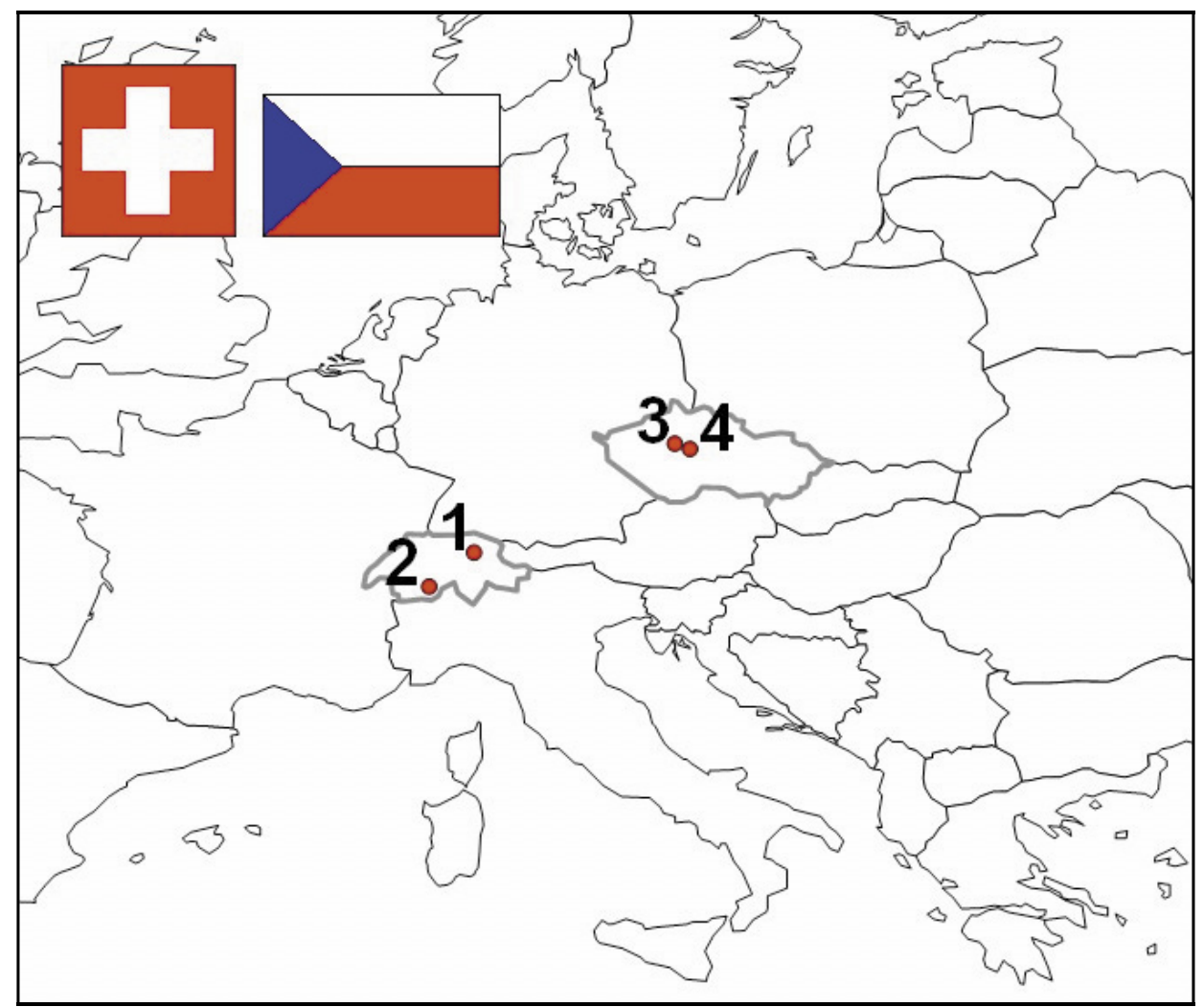

Fig. Geographical locations of the main organisers of the 3rd Swiss-Czech Symposium in 2005 (1 - University of Applied Sciences, Wädenswil CH; 2 - Lonza AG, Visp CH; 3 - Institute of Chemical Technology, Prague CZ; 4 - Lonza Biotec s.r.o, Kourim CZ)

its commercial use other than in traditional nutrition and food products (e.g. oxido-reduction and/or enantio- and regioselective reactions in organic chemistry [14][15]; total biosynthesis from simple carbon sources [16]; production of technical enzymes such as lipases and esterases, and low cost products, for instance feed enzymes [17]). Furthermore, yeast cell material can be a source of several substances which are beneficial to health or can be used in cosmetic applications (e.g. glycans, ceramides).

The commercial utilisation of yeast, a unicellular organism which combines the advantages of a eukaryotic expression system with those of a bacterial one, is supported by the following arguments:

- as a fast-growing organism, yeast can be easily cultivated to high cell densities (HCDC) in non-expensive mineral media and is therefore free from retroviral contaminations;

- in contrast to e.g. E. coli, components of yeast cells do not cause endotoxic (i.e. pyrogenic) reactions in humans;

- the 'food' yeasts are highly acceptable for the production of pharmaceuticals having GRAS affirmation (i.e. 'Generally Recognized as Safe');

- yeast usually expresses heterologous genes using a natively strong and tightly regulated promoter;

- yeast is able to secrete large amounts of functional protein into the culture broth, i.e. it performs many of the posttranslational modifications typically associated with higher eukaryots;

- yeast is easy to handle at large scale and during product recovery.

Since several criteria determine the choice of the best-suited expression system in biopharmaceutical production (i.e. target pharmacological activity, process cost-effectiveness, available physiological/genetic know-how and tools, patent situation, regulatory aspects), none of the systems available can be considered to be generally superior to the others. Currently, S. cerevisiae, $\mathrm{CHO}$ and BHK cells, and $E$. coli inclusion body are the best-established technologies worldwide for the manufacture of a vast variety of commercially relevant products [8], whereas E. coli, P. pastoris and baculovirus systems are preferred in fundamental research. It is therefore likely that issues relating to innovation or commercial competitiveness will be the reasons for a reassessment of the use of traditional (and non-conventional) yeast systems. As a result, a change in production technologies, which are now well-established and accepted by regulatory bodies, may occur. The following factors include opportunities for yeast technology that could hardly be envisioned some years ago:

- a number of noteworthy advances in the overexpression of recombinant proteins in yeasts, which have enabled the secretion of correctly folded, glycosylated or even 'humanised' [18][19] (and thus pharmacologically active) proteins;

- the frequent exclusion of the use of low-priced products derived from natural plant or animal sources due to strict requirements regarding consistent product quality, high purity and safety with respect to increasingly emerging diseases such as BSE;

- the expected expiry of numerous patents on biopharmaceuticals in the near future, which may open the market to bio-generica (for an overview see [20]). 


\section{What Was Gleaned from the Presentations and Posters?}

The choice of presentations successfully combined talks focussing on specific scientific challenges with more general presentations on e.g. (i) yeast genomics and the evolutionary history of yeasts [21][22], (ii) physiology of methylotrophic yeasts [23], and (iii) both scale-up and economical aspects of industrial yeast processes [24][25]. Thus, opportunities were provided to hear speakers from each stage of the process of turning innovative research results into successful industrial products. (Note: in this section only selected publications from symposium participants are cited.)

Pichia pastoris, a facultative methanol utilising yeast, was the centrepiece of most presentations, with topics that ranged from strain construction over technology development to implementation in large scale production. As a large number of various heterologous products from different sources have been expressed in recombinant $P$. pastoris [12], it has become an emerging competitor in the manufacture of biopharmaceuticals, especially where secreted proteins are concerned [8][9][11]. Since in many cases the product concentrations correlate with those of biomass, the extraordinarily high biomass concentrations $\left(>160 \mathrm{~g} \mathrm{l}^{-1}\right)$ achievable with this yeast also suggest high product building rates and yields, and thus sustainable cost-effective manufacturing. However, the high-cell-density cultivation of $P$. pastoris is generally considered to be more difficult to implement on a largescale than, for example, the cultivation of $E$. coli. Special care must be taken to keep the methanol concentrations below toxic levels while simultaneously maintaining sufficient methanol concentration/flux for induction. The following factors may impinge on process control:

- the intrinsic toxicity of methanol,

- the high heat produced during methanol oxidation, and

- increased formation of highly toxic metabolites as formaldehyde and hydrogen peroxide in the yeast cell.

It was the newly introduced ability of Pichia to secrete fully functional proteins with human-like posttranslational modifications [18][19] that has led to its being seen as a promising alternative to the rather laborious, but now established production of therapeutic proteins with mammalian cell cultures. Yeast is, without any doubt, suited for the production of proteins which are pharmacologically active without any glycosylation or with the type of glycosylation pattern that can be natively processed by the particular yeast (e.g. vascular endothelial growth factors, VEGFs). The heterogeneity of product variants and the still insufficient homology to human-type glycosylation currently cause the greatest problems in the production (and medical application) of glycosylated therapeutic proteins. Therefore, the improvement of glycosylation by chemical synthesis, biocatalysis or in vivo approaches is of major interest. Recent attempts to engineer yeast [18][19][26] and bacterial [27][28] strains to achieve a suitable $\mathrm{N}$-glycosylation look set to win the competition for the best suited production system for therapeutic proteins.

The still scare knowledge of the physiology of Pichia was considered in the light of extensive work on the physiology of wildtype strains of methylotrophs in continuous culture [23]. The convincing discussion revealed that it is fairly safe to assume that Pichia pastoris will behave in a similar way to Hansenula polymorpha (also named Pichia augusta). It was shown that, during simultaneous utilisation of mixtures of carbon-sources, the yeasts exhibit a number of interesting properties which result in increased productivity and process robustness as well as decreased heat evolution. However, conclusive evidence that these principles are generally applicable under conditions of heterologous protein production in high-cell-density fedbatch cultures has still to be found. Furthermore, there is a lack of systematic studies which address the fundamental question of to what extent the physiology of recombinant strains depends on the host's origin and on the way of implementing the heterologous gene [29]. It is particularly important to establish which behaviours are independent of strain engineering and thus can be readily utilised in process development without each new recombinant construct being investigated de novo. In this way, a rapid development of biopharmaceutical processes as required by the demands of the market can be accomplished more easily.

As most of the routinely used sensors provide data averaged for the whole population, they do not detect the heterogeneities of single cells with respect to their actual physiological state (and 'viability'). In certain presentations, flow cytometry in combination with specific fluorescent dyes was introduced as a promising method with which to study in detail the response of individual cells against environmental 'stress' and metabolic 'stress' during expression of heterologous proteins [30]. Such reactions arise in physiologically and/or structurally compromised organisms during, for instance, the progression of a fedbatch process as the individual cell's age and the environment is in a permanent state of change. To counteract these unwanted physiological reactions, they first need to be monitored and understood [31]. Such an in-depth understanding of the molecular physiology might form the basis for both the engineering of recombinant strains and the rational design of the most suitable control strategies to improve the productivity of a particular process.

\section{What Are the Future Prospects?}

We are still wondering whether yeast will play an increasingly important role in biotechnological manufacturing in the future. The 2005 Symposium clearly showed that in the field of applied yeast research there is much to be said not only for being aware of the latest studies but also for being familiar with earlier publications in which the gems of former findings were detailed. Also favoured are those who are capable of cross-disciplinary, goal-oriented thinking in biology, chemistry, and engineering [25].

The spontaneous flow of the discussions and the ongoing responses allow us to assume that the majority of attendees left the symposium convinced that their participation had been worthwhile and with a feeling of having learnt something! For this, our 
thanks go to the numerous official and un-official organisers, sponsors [2] and, of course, to the participants themselves for bringing this event to life. A special 'thank you' goes to Maggi Lussi Bell for her indefatigable linguistic help.

Don't miss the opportunity to attend the annual BioTech Conference in 2006 as well as the tri-annual Czech-Swiss/Swiss-Czech Symposium, which will be held for the fourth time in 2008.

See you in Wädenswil in 2006, and perhaps in 2008 in Prague!

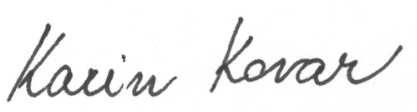

Prof. Dr. Karin Kovar

UAS Wädenswil

k.kovar@hsw.ch

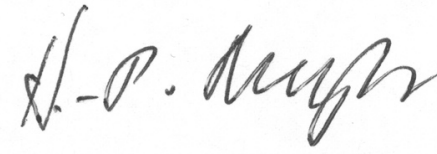

Dr. Hans-Peter Meyer

Lonza AG, Visp

hans-peter.meyer@lonzagroup.com

\section{Suggestions for Further Reading}

[1] 'Advances in Yeast Biotechnology. Summary of Presentations.' Eds. K. Kovar, T. Merseburger, D. Alexakis, Stutz Druck, Wädenswil, 2005.

[2] http://www.swiss-czech.net

[3] http://en.wikipedia.org

[4] 'Theoretical and Methodological Basis of Continuous Culture of Microorganisms.' Eds. I. Málek and Z. Fencl, Czech. Acad. Sci., Prague and Academic Press, London, 1966.

[5] Anonymus, Euro. Biotech. News 2005, 4, 43.

[6] '1st Czech-Swiss Symposium on Advanced Biotechnology.' Eds. H.-P. Meyer, C. Ganter, Chimia 1999, 53, 525-565.

[7] K. Kovar, K. Melzoch, I. Psenicka, H.P. Meyer, 'Large-scale Implementation of an Optimum Technology for High Productivity Processes with Recombinant Methylotrophic Yeasts.' Project Application E!3415 and CTI 7403.3 LSPP-LS, 2004.

[8] F.R.Schmidt,Appl.Microbiol. Biotechnol. 2004, 65, 363.

[9] T.U. Gerngross, Nat. Biotechnol. 2004, $22,1409$.

[10] C. Madzak, C. Gaillardin, J.M. Beckerich, J. Biotechnol. 2004, 109, 63.

[11] J.L. Cereghino, J.M. Cregg, FEMS Microbiol. Rev. 2000, 24, 45.

[12] http://faculty.kgi.edu/cregg/, List of Heterologous Proteins expressed in Pichia pastoris, April 2004.

[13] M.A. Romanos, C.A. Scorer, J.J. Clare, Yeast 1992, 8, 423.

[14] A. Liese, K. Seelbach, C. Wandrey, 'Industrial Biotransformations', WileyVCH, Weinheim, 2000.

[15] U. Blaser, E. Schmidt, 'Asymmetric Catalysis on Industrial Scale', WileyVCH, Weinheim, 2004.

[16] F.M. Szczebara, C. Chandelier, C. Villeret, A. Masurel, S. Bourot, C. Duport, S. Blanchard, A. Groisillier, E. Testet, P. Costaglioli, G. Cauet, E. Degryse, D. Balbuena, J. Winter, T. Achstetter, R. Spagnoli, D. Pompon, B. Dumas, Nat. Biotechnol. 2003, 21, 143 .
[17] A.F. Mayer, K. Hellmuth, H. Schlieker, R. Lopez-Ulibarri, S. Oertel, U. Dahlems, A.W.M. Strasser, A.P.G.M. van Loon, Biotechnol. Bioeng. 1999, 63, 373.

[18] S.R. Hamilton, P. Bobrowicz, R.C. Davidson, H. Li, T. Mitchell, J.H. Nett, S. Rausch, T.A. Stadheim, H. Wischnewski, S. Wildt, T.U. Gerngross, Science 2003, 301,1244

[19] S. Wildt, T.U. Gerngross, Nat. Biotechnol. 2005, 3, 119 .

[20] W. Hinderer, in 'Pharmaceutical Biotechnology', Eds. O. Kayser, R.H. Müller, Wiley-VCH, Weinheim, 2004, p. 119.

[21] F.S. Dietrich, S. Voegeli, S. Brachat, A. Lerch, K. Gates, S. Steiner, C. Mohr, R. Pohlmann, P. Luedi, S. Choi, R.A. Wing, A. Flevier, T.D. Gaffney, P. Philippsen, Science 2004, 304, 304.

[22] G. Giaever, A.M. Chu, L. Ni, C. Connelly, L. Riles, S. Véronneau, S. Dow, A. Lucau-Danila, K. Anderson, B. André, A.P. Arkin, A. Astromoff, M.E. Bakkoury, R. Bangham, R. Benito, S. Brachat, S. Campanaro, M. Curtiss, K. Davis, A. Deutschbauer, K.-D. Entian, P. Flaherty, F. Foury, D.J. Garfinkel, M. Gerstein, D. Gotte, U. Güldener, J.H. Hegemann, S. Hempel, Z. Herman, D.F. Jaramillo, D.E. Kelly, S.L. Kelly, P. Kötter, D. LaBonte, D.C. Lamb, N. Lan, H. Liang, H. Liao, L. Liu, C. Luo, M. Lussier, R. Mao, P. Menard, S.L. Ooi, J.L. Revuelta, C.J. Roberts, M. Rose, P. Ross-Macdonald, B. Scherens, G. Schimmack, B. Shafer, D.D. Shoemaker, S. Sookhai-Mahadeo, R.K. Storms, J.N. Strathern, G. Valle, M. Voet, G. Volckaert, C.-Y. Wang, T.R. Ward, J. Wilhelmy, E.A. Winzeler, Y. Yang, G. Yen, E. Youngman, K. Yu, H. Bussey, J.D. Boeke, M. Snyder, P. Philippsen, R.W. Davis, M. Johnston, Nature 2002, 418, 387.

[23] T. Egli, C.A. Mason, in 'Biology of Methylotrops', Eds. I. Goldberg, J.S. Roken, Butterworth-Heinemann, Boston, 1991, 173.

[24] F.W.J.M.M. Hoeks, C. van Tangerman, K. Gasser, H.M. Mommers, S. Schmid, K.C.A.A. Luyben, Can. J. Chem. Eng. 1997, 75, 1018 .
[25] H.-P. Meyer, J. Klein, Pharma. Chem 2005, January/February, 14.

[26] W. Vervecken, V. Kaigorodov, N. Callewaert, S. Geysens, K. De Vusser, R. Contreras, Appl. Environ. Microbiol. 2004, 70, 2639.

[27] M. Aebi, M. Wacker, International Patent WO 03/074687 A1, 2003.

[28] M. Wacker, D. Linton, P.G. Hitchen, M. Nita-Lazar, S.M. Haslam, S.J. North, M. Panico, H.R. Morris, A. Dell, B.W. Wren, M. Aebi, Science 2002, 298, 1790.

[29] H. Hohenblum, B. Gasser, M. Mauer, N. Borth, D. Mattanovich, Biotechnol. Bioeng. 2004, 85, 367.

[30] H. Hohenblum, N. Borth, D. Mattanovich, J. Biotechnol. 2003, 102, 281.

[31] V. Looser, F. Hammes, M. Keller, M. Berney, K. Kovar, T. Egli. Biotechnol. Bioeng. 2005 (in press, DOI: 10.1002/ bit20574). 